\title{
Design and Development of College Students' Employment Platform
}

\author{
Yufei Wang, Furong Li and Kun Zhang* \\ College of Ocean Information Engineering, Hainan Tropical Ocean University, Sanya, Hainan, 572022, \\ China \\ kunzhang@hainu.edu.cn \\ The corresponding author
}

Keywords: College students employment; Resource sharing; Internet

\begin{abstract}
In the era of the Internet, demand-oriented Internet business model and value creation is emerging, the current phenomenon of college students work-study is widespread, students often seek part-time channels are scattered, roadside advertising now lacks a focus on students Group of healthy part-time job information exchange platform, the study aims to establish an independent and systematic mode of operation through the website or APP in the form of integration scattered in colleges and universities, as well as social work for students to help the employer more quickly Better find part-time job, in line with the university's talent training strategy.
\end{abstract}

\section{Introduction}

With the development of Chinese university education, the number of college students has increased dramatically, the employment problem of college students has become more and more prominent. The employment situation of graduates has been challenged by college students in the face of severe employment situation and the influence of current financial crisis. After graduation, students can successfully employment, has become the general concern of the whole society hot issues. In recent years, the employment situation of college students is becoming more and more serious. In the late 1990s, the university enrollment caused the university graduates to excess, the employment pressure increased, the financial crisis makes the employment of college students more difficult. According to the "2013 China University Students Employment Report" data show that the national college graduates reached 699 million people, the overall contract status compared with the previous significant decline in undergraduate graduates signed only 35\%, down 12 percentage points over the same period last year, these The data once again verified the "history of the most difficult years of employment" argument; and 2014 China University student employment report pointed out that China will have 7.27 million graduate students, plus students who did not find a job last year, the employment situation will become more The more severe.

China's basic national conditions in employment can be summarized as "a large, more than three, one less." China's large population, the number of college graduates each year, but the employment of small jobs, which led to a large number of unemployed people each year, affecting the employment situation next year.

\section{Analysis of Current Employment Situation}

On the current situation, contemporary college students access to employment information are the main ways: all kinds of graduates employment market, job advertisements, supply and demand meeting, job fairs, Internet and headhunting companies. And these recruitment channels issued recruitment information and more complex, no specific industry classification. Therefore, college students will be a lot of time wasted in the career choice, rather than the time to prepare for the interview and written examination, which led to the 
success rate of employment is not particularly high. In addition, some talent recruitment will be held in time conflict, so that graduates are difficult to choose.

Therefore, the need for a timely employment information can be sent to the hands of graduates in time, but also to achieve between the school and school students choose the platform for employment.

\section{Domestic and international development}

Developed countries and regions in the relatively early stage of entering the market economy, higher education development is more mature, coupled with the field of foreign computer started earlier, relatively rapid construction of information technology, so its employment in the construction and development of university students relative A lot of maturity in our country. Many foreign university management tools operate more mature, and have a rather long background of capitalist development, which determines that their college students' employment platform has the advantages of long construction time, advanced equipment, relatively mature system development and standardization. In the United States, computer penetration is quite high, reaching almost every college student can use his computer to look up the information they need. In addition, with the opening and popularization of the Internet in recent years, the employment management department of graduates in the United States, each graduating college student and social employers unit as an organic whole, and the employment platform for undergraduates has been fully utilized.

At present, domestic portals provide employment pages and specialized employment websites. However, these websites not only serve graduates, but also provide extensive employment navigation with less pertinence. Therefore, more and more colleges and universities rely on their own strength or social forces, tailor their own employment information system. To enterprises, graduates, learning online recruitment and employment information system platform in the school employment in the school as the main target of service to colleges and universities to help graduates employment, business-oriented, to help employers choose the most suitable candidate as the goal, Set up a convenient, fast and efficient employment information service level. After the survey found that graduates in other domestic institutions a wide variety of employment networks, most are also self-developed system. According to the actual situation of our school, it is of great significance for us to develop our own employment platform that is suitable for our school. This is of great practical significance to the informatization and networking of our graduates' employment services and to the enhancement of the quality and guidance of employment guidance.

\section{The Structure of the System}

Recruitment information management system as a subsystem of human resources management, the user only has its own internal personnel management personnel. The whole system is for personnel recruitment manager, is divided into three parts. Including user information management, recruitment information management, candidate information management. User information management, including user information management and user information management, job information management, including recruitment of information management, recruitment information release, recruitment job management candidate information management, including candidate basic information management, candidate education information management, candidates work experience information Management, project information management by candidates, IT skills information management candidates, candidate information management of the language, job candidates candidate information management. 


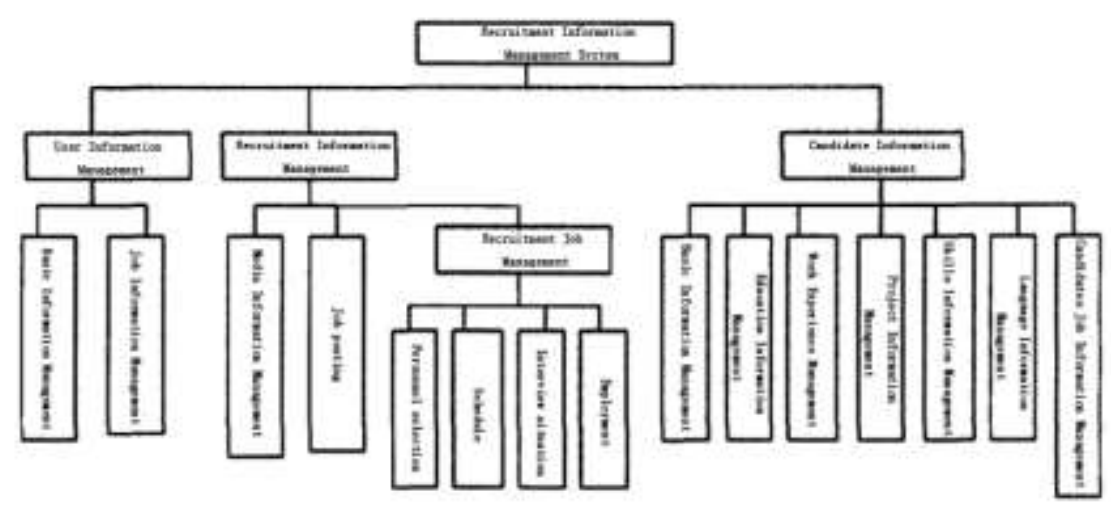

Figure 1. Employment management system functional structure

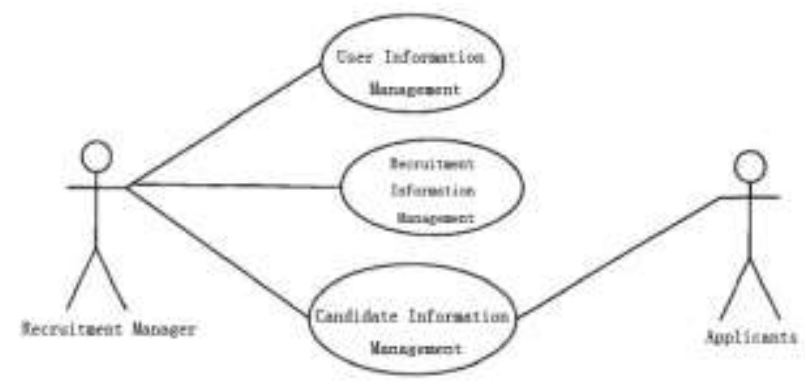

Figure 2. Use simulation diagram

Hiring information management system is a personnel management platform that contains three subsystems. Due to the B / S design based on WEB, the physical implementation of each subsystem can be regarded as the relative path of the WEB application on the WEB server, that is, the relative WEBSubfolders of the site file.In the final realization of the model, the use of component diagrams and configuration diagrams to represent the entire recruitment information management system implementation model.

\section{Other requirements for employment service platform}

In order to solve the employment problem for undergraduates in the severe employment situation, it is far from enough to rely solely on a website for recruitment. We also need to rely on the joint efforts of enterprises and public institutions in the education sector of government departments and even social forces. Government employment service agencies of all types of employment service agencies personnel exchange service agencies, all types of graduates employment guidance service agencies should actively for students intern school, the new graduates to build networking information and information exchange, provide policy advice, Career guidance and other services. Labor security, human resources, education, civil affairs and finance departments should further strengthen the contact, establish a mechanism for coordinating the employment of graduates, and improve the campus employment information network. While possessing the excellent resources of the network, it is suggested that all the Communist Youth League committees in each province establish an employment service center for the network Recruiting enterprises and institutions to build a major offline interactive platform for colleges and universities, with the portals of all kinds of special recruitment will be conducted, will play an unexpected role in promoting; due to the establishment of a unified campus portal, on the other hand, won the provincial The employment data, employment orientation and employment dynamics of undergraduates in the university provide the PICC with another means of management. It is recommended that the PICC provide policies such as social security accounts 
and data loading and sharing for the management of campus recruitment platform so as to provide convenience for self-management for university students who go to society through the platform and provide basis and measures for the unified management of the PICC. As an operational support for campus recruitment website, the operating enterprise unit helps to promote campus channel resources, network platform support, Internet hardware and software support, and mobile Internet channel support so that the campus recruitment platform can move forward orderly and continuously.

\section{Summary}

At present, almost all of the campus portals involve the employment of college graduates. They are one of the jobs of "career guidance centers" on various campuses. Their sources of information are true, the requirements are clarified, and one of the objects that university students use for daily viewing and use. However, it is only open to employment database of Employment Guidance Center. Without the real-time and interactive information, it is very hard to provide real employment guidance to students and only provide more employment opportunities. At the same time, there are more and more recruitment websites in the society. Although there are a lot of functions, there are few websites for employment of college graduates. It is difficult to provide overall help for the employment of college students. To promote the employment of college students can not simply start from the short-term employment policy, but from the overall quality of workers to improve the overall social start. That is, employment is not a simple employment issue, but involves issues such as education, employment, household registration and social security. Correspondingly, education, human resources, social security, civil affairs and other departments of the entire society need to be fully co-ordinated. As far as possible, the existing resources of the society are concentrated to provide systematic and comprehensive help for the employment of university students. Students should not be preparing for employment starting from graduation, but from the time of school planning, and all of this functionality can be provided through the Internet in the form of the majority of students.

\section{Acknowledgement}

This research was financially supported by the 2015 Innovative Entrepreneurship Project of College Students in Hainan Province (No.20150120).

\section{References}

[1] J. Tan: An Analysis of the Employment Situation of College Students and the Countermeasures, Journal of Ezhou University, (2012) No.1, p. 62-64.

[2] B.Y. Fu, X.R. Zhu, B. Ma: On the Influence of Micro - letter Platform on Contemporary College Students, Wisdom of the times, (2015) No.10, p. 171.

[3] H.L. Li: Research on the Employment Environment of College Students, Shenyang: Shenyang Normal University, 2014.

[4] K.X. Zhong, Y.T. Liu: Knowledge Management and Core Competence of College Students' Employment, Research on Educational Development, (2013) No.11, p. 57-62. 